Research article

Open Access

\title{
Chromogenic in situ hybridization (CISH): a novel alternative in screening archival breast cancer tissue samples for HER-2/neu status
}

\author{
Manuelito A Madrid and Raymundo W Lo
}

Institute of Pathology, St Luke's Medical Center, Quezon City, Philippines

Corresponding author: Manuelito A Madrid, migalf22@yahoo.com

Received: 23 Apr 2004 Revisions requested: 1 Jun 2004 Revisions received: 23 Jun 2004 Accepted: 29 Jun 2004 Published: 29 Jul 2004

Breast Cancer Res 2004, 6:R593-R600 (DOI 10.1186/bcr915)

(C) 2004 Madrid and Lo; licensee BioMed Central Ltd. This is an Open Access article: verbatim copying and redistribution of this article are permitted in all media for any purpose, provided this notice is preserved along with the article's original URL.

\begin{abstract}
Background Chromogenic in situ hybridization $(\mathrm{CISH})$ is emerging as a practical, cost-effective, and valid alternative to fluorescent in situ hybridization in testing for gene alteration, especially in centers primarily working with immunohistochemistry (IHC).

Methods We assessed Her-2/neu alteration using $\mathrm{CISH}$ on formalin-fixed paraffin-embedded primary invasive ductal carcinoma tumors in which IHC (CB11 antibody) had previously been performed, and we compared the results with IHC. The 160 selected cases were equally stratified randomly into the four IHC categories (scores of $0,1+, 2+$, and $3+$ ). We also compared age at diagnosis and tumor histologic grade with $\mathrm{IHC}$ and $\mathrm{CISH}$ Her-2/neu.

Results We were able to perform and evaluate $\mathrm{CISH}$ successfully on all cases. The agreement between $3+\mathrm{IHC}$ and $\mathrm{CISH}$-amplified cases as well as between all $\mathrm{IHC}$ and $\mathrm{CISH}$ Her-

$2 /$ neu negative cases was $100 \%$, and the concordance on all positive cases was $72.50 \%$, with an overall agreement of $86.25 \%$. All the discordant cases had $2+\mathrm{IHC}$ scores. Although we noted Her-2/neu positivity more in premenopausal women, the age at diagnosis was not significantly associated with IHC or $\mathrm{CISH}$ results. Similarly, although the small group of welldifferentiated tumors was apparently Her-2/neu negative in both tests, no significant association was noted between any tumor histologic grade and either $\mathrm{IHC}$ or $\mathrm{CISH}$ results.

Conclusions $\mathrm{CISH}$ is easily integrated into routine testing in our laboratory. It is a necessary adjunct in determining the subset of non-amplified IHC-positive invasive tumors that will not benefit from trastuzumab therapy. Those cases with $2+\mathrm{IHC}$ results will be triaged and subjected to $\mathrm{CISH}$. Her-2/neu testing should be done on all breast cancer cases regardless of age at presentation and tumor histologic grade.
\end{abstract}

Keywords: breast cancer, chromogenic in situ hybridization, fluorescence in situ hybridization, Her-2/neu, immunohistochemistry

\section{Introduction}

The Her-2/neu proto-oncogene, also known as c-erbB-2, is a member of the type I growth factor receptor gene family and is located in the long arm of chromosome 17 (17q1221.32) [1]. It encodes a $185 \mathrm{kDa}$ cytoplasmic membrane glycoprotein involved in tyrosine kinase signal transduction for epithelial cell proliferation, including the breast epithelium [2].

In $20-30 \%$ of breast carcinomas, Her-2/neu status is altered, and this is manifested either as amplification of the gene or overexpression of the protein product [3]. Such alteration has been associated with poor prognosis and with resistance to conventional adjuvant chemotherapy and tamoxifen, regardless of the nodal or hormone receptor status [4-8]. Moreover, patients with breast carcinomas with amplified or overexpressed Her-2/neu can benefit from anthracycline-based regimens as well as trastuzumab (Herceptin), a recombinant humanized monoclonal antibody against the Her-2/neu protein [9].

Tumor Her2/neu is generally assessed as protein overexpression by using immunohistochemistry (IHC), and patients with tumors that either have $2+$ or $3+$ results with this method become good candidates for treatment with trastuzumab. 
However, studies indicate that Her2/neu determined as gene amplification provides better prognostic information and is associated with a better response to trastuzumab [10-12]. A subset of patients with tumors having $2+\mathrm{IHC}$ results were found to show no response to the drug, whereas all those having gene amplification responded favorably. Nevertheless, a negative (0 or $1+$ ) or a $3+$ Her$2 /$ neu IHC correlates well with a negative or positive Her$2 /$ neu gene amplification, respectively.

Her-2/neu gene amplification is primarily detected by in situ hybridization and uses fluorescence (FISH) to detect the signals. This method is both cumbersome and expensive and needs a fluorescence microscope, appropriate filters, and a sophisticated camera; it is therefore not practical as a screening tool. Chromogenic in situ hybridization $(\mathrm{ClSH})$ is a recently introduced method, and although it makes use of the in situ hybridization technology of FISH, it also takes advantage of the chromogenic signal detection of $\mathrm{IHC}$ that can be detected with the ordinary light microscope and costs one-quarter as much as FISH. $\mathrm{CISH}$ is potentially able to detect Her-2/neu gene amplification and to minimize, if not eliminate, the false positive fraction with the IHC procedure. Here we report an evaluation of the CISH assay in St Luke's Medical Center (SLMC), Philippines.

\section{Methods}

\section{Inclusion criteria}

This study focused on in-patient female breast cancer tissue samples with final histopathologic diagnosis of invasive ductal carcinoma of no special type, with archival paraffin blocks, and with prior Her-2/neu alteration determined by IHC from 1 January 2000 to 31 December 2001 in our laboratory.

\section{Method}

IHC was previously determined with CB11 antibody (Zymed Laboratories) on breast tumor samples fixed in buffered formalin and embedded in paraffin. Only one pathologist reviewed the Her-2/neu results of all IHC cases in the period covered, reassessing them in accordance with the US Food and Drug Administration-approved Her$2 /$ neu IHC scoring guidelines [10]. Immunoreactivity was defined as negative with a score of 0 (no staining in all cells or very weak membrane staining in less than $10 \%$ of the tumor cells) or $1+$ (weak perceptible partial membrane staining in more than $10 \%$ of the tumor cells), and was defined as positive with a score of $2+$ (weak to moderate complete membrane staining in more than $10 \%$ of the tumor cells) or $3+$ (strong complete membrane staining in more than $10 \%$ of the tumor cells). Areas with intraductal carcinoma were excluded from the evaluation.
Her-2/neu gene amplification was then analyzed with $\mathrm{CISH}$ on cases selected through stratified random sampling into the four $\mathrm{IHC}$ categories. Each category contained an equal number of samples (40 samples in each $\mathrm{IHC}$ category), for a total of 160 samples.

The CISH assays were run by one technologist in the Histopathology Section of the Institute of Pathology following the protocol of Zymed. Thereafter, CISH results were read by the same pathologist who was blinded to the previous IHC results. CISH was assessed on invasive ductal carcinoma areas only; foci of intraductal carcinoma were excluded from the analysis of results. Table 1 shows the recommended $\mathrm{ClSH}$ scoring by Zymed.

In addition, the patients' ages were arbitrarily grouped as either premenopausal (less than 50 years) or postmenopausal (50 years or more). The histologic grades of the invasive tumor foci were assessed in the $\mathrm{IHC}$ and $\mathrm{CISH}$ slides by using the modified Bloom-Richardson classification [13].

\section{CISH procedure for formalin-fixed paraffin-embedded breast cancer tissue samples}

In brief, tissues 4-5 $\mu \mathrm{m}$ thick were mounted on Histogriptreated microscope slides, dried at $37^{\circ} \mathrm{C}$, and baked for 24 hours at $60^{\circ} \mathrm{C}$. The slides were deparaffinized for $15 \mathrm{~min}$ three times in xylene at room temperature $\left(22-27^{\circ} \mathrm{C}\right)$ and washed for 2 min three times in 100\% ethanol at room temperature.

The slides were microwaved in SPOT-Light Tissue Heat Pretreatment Buffer for $10 \mathrm{~min}$ at $92^{\circ} \mathrm{C}$ and washed for 3 min twice in phosphate-buffered saline (PBS). They were covered with $100 \mu \mathrm{l}$ SPOT-Light Tissue Pretreatment Enzyme for $10 \mathrm{~min}$ at $37^{\circ} \mathrm{C}$ and washed for $2 \mathrm{~min}$ three times in PBS at room temperature. The slides were then dehydrated in $70 \%, 85 \%, 95 \%$, and $100 \%$ ethanol for 2 min each, then air-dried.

Denatured probe $(15 \mu \mathrm{l})$ was added to the center of each sample and covered with a $24 \mathrm{~mm} \times 32 \mathrm{~mm}$ coverslip, the edges of which were sealed with thin layer of rubber cement to prevent the evaporation of probe solution during incubation. The slides were denatured at $94^{\circ} \mathrm{C}$ for $3 \mathrm{~min}$ and placed in a dark humidity box for $16-24$ hours at $37^{\circ} \mathrm{C}$.

After removal of the rubber cement and coverslip, the slides were immersed in $0.5 \times$ SCC buffer in a Coplin jar for 5 min at $75^{\circ} \mathrm{C}$. They were then washed for 2 min three times in PBS-Tween 20 buffer at RT.

The slides were submerged in peroxidase quenching solution and then washed for 2 min three times with PBS, after 
Table 1

Evaluation of Her-2/neu gene status using chromogenic in situ hybridization

\begin{tabular}{ll}
\hline Amplification & Her-2/neu gene status \\
\hline High-level & $>10$ copies or large cluster of amplicon per nucleus in $>50 \%$ of cancer cells \\
Low-level & $6-10$ copies or small cluster of amplicon per nucleus in $>50 \%$ of cancer cells \\
None & $1-5$ copies per nucleus of cancer cells ${ }^{b}$ \\
\hline
\end{tabular}

aVerify gene amplification or chromosome 17 aneuploidy with SPOT-Light Chromosome 17 Centromeric Probe. blf 3-5 copies per nucleus, verify chromosomal aneuploidy with SPOT-Light Chromosome 17 Centromeric Probe.

which endogenous biotin blocking was performed with Reagent A (100 $\mu$ l of CAS Block).

Using Zymed's SPOT-Light Detection Kit, $100 \mu \mathrm{l}$ each of fluorescein isothiocyanate-labelled sheep anti-digoxigenin, horseradish peroxidase-labelled goat anti-fluorescein isothiocyanate, and diaminobenzidine chromogen were sequentially added to the slides, with three 2 min rinses with PBS-Tween between the addition of reagents.

The slides were counterstained with $150 \mu$ of Gill-2 hematoxylin and incubated for $3 \mathrm{~min}$. They were then dehydrated with a graded series of alcohol, cleared in xylene, and mounted with a coverslip.

\section{Statistics}

All CISH data were compared with the previous $\mathrm{IHC}$ results with the use of descriptive statistics and the $\chi^{2}$ test for association. Similarly, age and tumor histologic grade were correlated with the IHC and CISH Her-2/neu with the same statistical methods. $P<0.05$ was considered statistically significant.

\section{Results}

There were a total of 681 breast cancer Her-2/neu determinations in 2000-2001, 245 of which (35.98\%) were inpatient cases. Of the in-patient cases, 104 (42.45\%) had positive Her-2/neu overexpression. One hundred and sixty in-patient cases were randomly selected for the study. The ages ranged from 24 to 77 years, with a median of 51 and a mean of 51.11 (standard deviation 10.86). Seventy-four of the $(46.25 \%)$ patients were less than 50 years of age.

All 160 tests were successfully performed with the Zymed protocol for $\mathrm{CISH}$. At least two detectable amplicons per tumor nucleus were observed, and these served as the internal control. In addition, a highly amplified positive control was run simultaneously with each test.

$\mathrm{CISH}$ results were evaluated with the light microscope at low-power and high-power magnification. Diaminobenzidine background staining was variably noted, but this was not sufficient to interfere with the interpretation of the $\mathrm{CISH}$ signals. Amplified cases showed at least six signals per nucleus; distinct clustering of amplicons was also obtained. Those cases reported as having no amplification or low amplification were not verified further for chromosome 17 aneuploidy.

Table 2 shows the $\mathrm{CISH}$ assay outcomes of the 160 cases in relation to the $\mathrm{IHC}$ category and tumor histologic grades. Of the 160 cases, 80 were IHC positive and 80 were IHC negative. With the $\mathrm{CISH}$ assay, 58 (36.25\%) of the 160 cases showed Her2/neu gene amplification. Of the 58 amplified cases, 17 (29.31\%) showed low amplification and 41 (70.69\%) showed high amplification. Forty of the $58 \mathrm{CISH}$-amplified cases had $3+\mathrm{IHC}$ results, and $18 \mathrm{had}$ $2+$ results. Most of the tumors were of histologic grade 2 (70\%), followed by grade $3(27.5 \%)$, then grade $1(2.5 \%)$.

Table 3 shows the correlation of $\mathrm{CISH}$ and IHC in 160 breast tumor samples. There was a statistically significant difference $(P=0.000)$ in the percentage of those without amplification between IHC-negative (100\%) and IHC-positive $(28 \%)$ cases; only positive IHC tended to have amplification. There were 22 IHC-positive cases that subsequently showed no gene amplification with $\mathrm{CISH}$, all of which had 2+ IHC scores.

The agreement between $3+\mathrm{IHC}$ and $\mathrm{CISH}$-amplified cases was $100 \%$. The concordance between IHC and $\mathrm{CISH}$ on all negative cases was $100 \%$, whereas the concordance on all positive cases was $72.50 \%$, with an overall agreement of $86.25 \%$.

Table 4 shows the association between age stratum (menopausal status), tumor histologic grade, IHC, and $\mathrm{CISH}$. Many more patients less than 50 years old (premenopausal) seemed to be Her-2/neu positive and amplified, whereas more patients 50 years old and older (postmenopausual) seemed to be Her-2/neu negative and non-amplified. However, these associations were not statistically significant $(P=0.156)$.

Similarly, no significant association was noted between age and histologic grade $(P=0.658)$.

Table 5 shows the association between results of Her2/ neu alteration with the histologic grades of the tumor. All histologic grade 1 cases (of which there were only four) did 
Table 2

Breast tumor samples and their corresponding immunohistochemistry (IHC), chromogenic in situ hybridization (CISH) results, and tumor histologic grade

\begin{tabular}{|c|c|c|c|c|c|c|c|}
\hline \multirow[t]{2}{*}{ IHC score } & \multirow[t]{2}{*}{ No. of tests } & \multicolumn{3}{|c|}{ CISH amplification } & \multicolumn{3}{|c|}{ Histologic grade } \\
\hline & & Negative & Low & High & 1 & 2 & 3 \\
\hline 0 & 40 & 40 & 0 & 0 & 1 & 33 & 6 \\
\hline $1+$ & 40 & 40 & 0 & 0 & 3 & 28 & 9 \\
\hline $2+$ & 40 & 22 & 8 & 10 & 0 & 24 & 16 \\
\hline $3+$ & 40 & 0 & 9 & 31 & 0 & 27 & 13 \\
\hline Total & 160 & 102 & 17 & 41 & 4 & 112 & 44 \\
\hline
\end{tabular}

Table 3

Correlation of chromogenic in situ hybridization and immunohistochemistry in archival breast tumor samples

\begin{tabular}{llll}
\hline \multirow{2}{*}{ Chromogenic in situ hybridization } & \multicolumn{2}{c}{ Immunohistochemistry } & Total \\
\cline { 2 - 4 } & Negative $(0$ and 1+) & Positive $(2+$ and 3+) & 102 \\
No amplification & 80 & 22 & 58 \\
With amplification & 0 & 58 & 160
\end{tabular}

\section{Table 4}

Comparison of age strata with tumor histologic grade, immunohistochemistry and chromogenic in situ hybridization results

\begin{tabular}{llll}
\hline Parameter & Age $<50$ & Age $\geq 50$ & Total \\
\hline Immunohistochemistry & & & \\
Negative $(0$ and $1+)$ & $33(41.25 \%)$ & $47(58.75 \%)$ & 80 \\
Positive $(2+$ and $3+)$ & $41(51.25 \%)$ & $39(48.75 \%)$ & 160 \\
Total & 74 & 86 & 102 \\
Chromogenic in situ hybridization & & $59(57.84 \%)$ & 58 \\
No amplification & $43(42.16 \%)$ & $27(46.55 \%)$ & 160 \\
With amplification & $31(53.44 \%)$ & 86 & 4 \\
Total & 74 & $4(100.00 \%)$ & 112 \\
Histologic grade & $0(0.00 \%)$ & $59(52.68 \%)$ & 44 \\
1 & $53(47.32 \%)$ & $23(52.23 \%)$ & 160 \\
2 & $21(47.73 \%)$ & 86 & \\
Total & 74 & & \\
\end{tabular}


Table 5

\begin{tabular}{|c|c|c|c|}
\hline \multirow[t]{2}{*}{ Histologic grade } & \multicolumn{3}{|c|}{ Immunohistochemistry Her2/neu (\%) } \\
\hline & Negative $(0$ and $1+)$ & $2+$ & $3+$ \\
\hline 1 & $4(5.00)$ & $0(0.00)$ & $0(0.00)$ \\
\hline 2 & $61(76.25)$ & $24(60)$ & $27(67.50)$ \\
\hline 3 & $15(18.75)$ & $16(40)$ & $13(32.50)$ \\
\hline \multirow[t]{3}{*}{ Histologic grade } & \multicolumn{3}{|c|}{ Chromogenic in situ hybridization Her2/neu (\%) } \\
\hline & \multirow[t]{2}{*}{ No amplification } & \multicolumn{2}{|c|}{ With amplification } \\
\hline & & Low & High \\
\hline 1 & $4(3.92)$ & $0(0.00)$ & $0(0.00)$ \\
\hline 2 & 75 (73.53) & $12(70.59)$ & $25(60.98)$ \\
\hline 3 & $23(22.55)$ & $5(29.41)$ & $16(39.02)$ \\
\hline
\end{tabular}

not overexpress or amplify Her2/neu. No significant association was noted between histologic grade and IHC scores. Similarly, no association was observed between histologic grade and $\mathrm{CISH}$ results.

\section{Discussion}

Her-2/neu status can be detected by analyzing the number of gene copies by Southern blotting, PCR, or FISH, or the amount of expressed protein can be ascertained by Western blotting, enzyme-linked immunosorbent assay, or IHC. The two most widely used methods at present are $\mathrm{IHC}$ and FISH because they are able to evaluate Her-2/neu in formalin-fixed paraffin-embedded archival tissues.

Most Her-2/neu studies have been performed by IHC, which detects overexpression of the Her-2/neu protein product on the cell membrane of tumor cells. This study used the CB11 monoclonal antibody, which, like the standardized polyclonal HercepTest, is directed against the intracytoplasmic domain of the Her2/neu molecule $[11,14]$.

IHC is widely accessible and easy to perform at a reasonable cost. However, this semi-quantitative procedure is beset by technical artifacts, sensitivity differences between different antibodies, and subjective interpretation, resulting in interobserver variability between pathologists [15]. Studies reveal the oversensitivity of US Food and Drug Administration-approved HercepTest, with a false positive rate as high as $50 \%[10,11]$. Thomson and colleagues concluded that in cases with an IHC stain intensity of $1+$ or $2+$, the interobserver agreement is poor and the predictive value is unsatisfactory for clinical use; they recommended additional testing, preferably with FISH [16].
FISH is a fairly objective and quantitative procedure in detecting Her-2/neu gene amplification on the nuclei of tumor cells. The drawbacks of this procedure are its steep cost (10 times that of $\mathrm{IHC}$ ), sophistication, the need for a fluorescence microscope, the temporary signal (it requires a special camera), and its inability to detect and assess tumor histomorphology.

Her-2/neu overexpression detected by $\mathrm{IHC}$ is highly correlated with gene amplification detected by FISH (as high as $98 \%$ concordance) [17]. However, 3-15\% of breast carcinomas show moderate Her-2/neu membrane staining without evidence of amplification. They most often represent highly sensitive nonspecific staining (false positive) and, rarely, either enhanced mRNA transcription in the absence of amplification or gene amplification that is below the detection level of in situ hybridization methods $[11,18,19]$.

Kakar and colleagues concluded that $\mathrm{IHC}$ is appropriate for the initial Her-2/neu assessment, but patients whose tumors scored less than $3+$ (particularly those interpreted as $2+$ ) would benefit from FISH to assess Her-2/neu status more accurately and to avoid inaccurate prognostication and inappropriate treatment [20].

$\mathrm{CISH}$ is a recent advancement in Her-2/neu detection. It uses a robust unique-sequence probe developed for in situ hybridization and is a promising practical alternative to FISH. After the first CISH study by Tanner and colleagues [21], seven other reports favorably validated $\mathrm{CISH}$ results [22-28]. The concordance between $\mathrm{CISH}$ and $\mathrm{FISH}$ ranged from $85 \%$ [25] to as high as $100 \%[23,24]$. All these reports noted the advantages of $\mathrm{CISH}$ over FISH: it requires an ordinary microscope; the method is less cum- 
bersome and more economical; the signal intensity is permanent; and pathologists are familiar with $\mathrm{IHC}$ signals and are able to correlate findings with the underlying tumor histomorphology. CISH allows observers to select fields of invasive ductal carcinoma, avoiding foci of intraductal carcinoma for which Her-2/neu has a different clinical significance. CISH is a specific, sensitive, and easily applicable method for the detection of Her-2/neu gene amplification, and it can be used together with $\mathrm{IHC}$ for the evaluation of patients with breast carcinoma [22]. Ross and colleagues recently reviewed the current status of Her-2/neu testing, and they concluded that $\mathrm{CISH}$ is a more convenient genebased technique that is 'waiting in the wings' [29].

In this present study, the concordance between $3+\mathrm{IHC}$ and $\mathrm{CISH}$-amplified cases was $100 \%$ (40 of 40 ), denoting all gene amplified cases to be overexpressing the Her-2/ neu protein. In contrast, the agreement on $2+\mathrm{IHC}$ and $\mathrm{CISH}$-amplified cases was only $45 \%$, which is lower than previously reported (93\%) [26]. The $13.75 \%$ (22 of 160) IHC-positive/CISH non-amplified tumors in this study, all of which had 2+ IHC scores, is higher than the $6 \%$ false positive result by Zhao and colleagues [24], although comparable to the $17 \%$ result (IHC CB11 versus FISH) obtained by Tubbs and colleagues [11]. Apparently, we find that the $2+\mathrm{IHC}$ score is equivocal when compared with $\mathrm{CISH}$. This subset might benefit from further $\mathrm{CISH}$ reflex testing. All negative IHC cases were $\mathrm{CISH}$ non-amplified, showing complete agreement of all negative results. The $86.25 \%$ overall concordance between IHC (using CB11 antibody) and $\mathrm{CISH}$ in this study is lower than the previous reports $(94-96 \%)[24,30]$. We concur with Sapino and colleagues that gene amplification analysis can be avoided in all 0,1+, and $3+\mathrm{IHC}$ cases because results are predictable from $\mathrm{IHC}$ and are completely concordant with $\mathrm{CISH}$ [30]. The utility of $\mathrm{CISH}$ is therefore in further testing Her-2/neu alteration on equivocal cases in $\mathrm{IHC}$, which remains the primary screening method. The combined IHC-CISH algorithm provides an economical and comprehensive Her-2/neu data to guide clinicians in mapping treatment options.

The low-amplified CISH category (6-10 signals) was the most difficult to interpret, requiring an accurate enumeration of gene copy. Signal clustering, more probably a result of intrachromosomal amplification of homogeneously staining regions, was immediately apparent in highly amplified cases and was easily evaluated $[23,31]$.

A test for chromosome 17 aneuploidy was not performed on non-amplified and low-amplified CISH assays, because recent studies showed that it makes the analysis more costly and time consuming without adding relevant data, apart from reporting the recommended number of nuclear amplicons and acting as another form of internal control for the hybridization reaction [11,18,21-24]. In addition, although the manufacturer (Zymed) suggested that chromosome 17 aneuploidy be tested on all gene-amplified cases, we concur with Vera-Roman and colleagues [28], who correctly pointed out that because most polysomy results fall within the gray area of three to five signals, setting the threshold of cutoff signal points to a high of six or more (as in this study) virtually eliminates the polysomy variable.

This study did not observe IHC-negative $\mathrm{CISH}$-amplified tumors. This can probably be explained by the fact that this was a single-institution study likely to have uniformly fixed and processed tumor tissue paraffin blocks as well as a uniform antigen retrieval technique, both of which make highquality $\mathrm{IHC}$ easier. Zhao and colleagues reported occasional IHC-negative $\mathrm{ClSH}$-amplified cases, and they considered that these represent a small undetermined percentage that amplified Her-2/neu without overexpression [24]. The same study and other FISH studies also noted rare $3+\mathrm{IHC}$ tumors that were non-amplified (false positive) $[11,24,30]$. The reasons offered for the IHC$\mathrm{CISH}$ discrepancies are similar to those between IHC and $\mathrm{FISH}$, as previously stated in the present report.

The causes of testing failure and false negativity offered by previous $\mathrm{CISH}$ studies were an absence of tumor on the section, an inability to score owing to high background, a low signal intensity despite repeated trials, an absence of signals from the internal control, and the use of alcohol-formalin-acetic acid fixative [22-24,26]. It was further noted that heat pretreatment and digestion with pepsin are the most critical procedures for optimized $\mathrm{CISH}$ performance, and that successful rates of $\mathrm{CISH}$ were low when 20-yearold tissue blocks were used [24].

Sauer and colleagues [32] correlated IHC and FISH results with clinical prognosis. They noted that IHC/FISH-positive cases as well as FISH-positive-only cases had the same prognosis regarding survival, whereas IHC-positive-only cases had a prognosis similar to that of IHC/FISH-negative tumors. In contrast, IHC-negative/FISH-positive cases had a survival probability similar to that of IHC/FISH-positive cases. The same authors concluded that if only $\mathrm{IHC}$ were used as a primary tool, IHC-negative/FISH-positive cases would be missed; those women would not have the benefit of trastuzumab and their survival would be adversely affected. In contrast, IHC-positive-only tumors seem to belong to a better prognostic group, and failure to detect them would probably not have a negative effect on survival [32].

Because clinical outcome studies have yet to address the utility of the low-amplified and high-amplified $\mathrm{CISH}$ results, especially the uncertain significance of the low-amplified group, these categories are still in flux. This limitation not- 
withstanding, there is still value in reporting such amplified groups separately at present, pending whatever clinical associations will be obtained in the future. Intraobserver and interobserver variability on reporting low-amplified and high-amplified $\mathrm{CISH}$ results were not included in this study, although the pathologist who interpreted the $\mathrm{CISH}$ assays consistently applied the criteria set by the manufacturers.

Breast cancer in premenopausal women has a different biopathologic profile from that in older patients, with a predominance of unfavorable prognostic parameters, including a higher frequency of grade 3 tumors and more frequent Her2/neu overexpression [33]. Young age serves as a surrogate measure of adverse prognostic profiles [34]. This study failed to establish the association between menopausal status, which was arbitrarily set at 50 years and above, and Her2/neu alteration.

Her2/neu amplification was directly correlated with grade and histologic type of breast cancer $[27,30,35]$. Sapino and colleagues suggested that, on the basis of tumor grade and histologic type, the pathologist should be able to indicate to the oncologist which breast cancer requires Her2/ neu analyses [30]. However, while none of the four well-differentiated tumors showed Her2/neu amplification or overexpression, no significant correlation was gathered in this study in terms of Her2/neu status and histologic grade; we therefore still subscribe to testing Her2/neu on all newly diagnosed breast cancers. Overall, age distribution of breast cancer patients and tumor histologic grade did not significantly predict $\mathrm{IHC}$ and $\mathrm{CISH}$ Her2/neu status.

\section{Conclusion}

The study has successfully evaluated Her2/neu $\mathrm{CISH}$ as a molecular biology procedure that is easily integrated into routine testing in our laboratory. $\mathrm{CISH}$ is a promising, practical alternative to FISH that can be used in conjunction with $\mathrm{IHC}$, which remains the first screening procedure of choice. IHC is easy to perform, relatively inexpensive, and able to detect a majority of breast cancer patients whose tumors have negative $(0$ or $1+$ ) or positive $(3+)$ Her-2/neu status, all three of which have complete concordance with $\mathrm{CISH}$.

In the SLMC laboratory setup, Her2/neu CISH can be done directly at the request of the physician. Because discrepancies between the two Her-2/neu tests were observed in the $2+\mathrm{IHC}$ category, cases with $2+\mathrm{IHC}$ results will be triaged and subjected to CISH before trastuzumab therapy. This IHC-CISH test stratification not only identifies the IHC false-positive subset that will not benefit from trastuzumab but also keeps testing costs for Her-2/ neu status at a reasonable minimum.
Her2/neu testing has achieved a standard-of-practice status in the USA [28], and it should be performed on all breast cancer cases regardless of age at presentation and tumor histologic grade.

\section{Competing interests}

None declared.

\section{Acknowledgements}

This study was made possible by the support and funding of the Institutional Review Board (IRB) of SLMC. We thank Mr Warlito B Vallejos RMT for his technical assistance in the $\mathrm{CISH}$ assays. We also thank Glenwood Technologies International, Inc., for the $\mathrm{CISH}$ probes and kits of Zymed.

\section{References}

1. Popescu NC, King CR, Kraus MH: Localization of the human erbB-2 gene on normal and rearranged chromosomes 17 to bands q12-21.32. Genomics 1989, 4:362-366.

2. Akiyama T, Sudo C, Ogawara H, Toyoshima K, Yamamoto T: The product of c-erbB-2 gene. A 185-kilodalton glycoprotein with tyrosine kinase activity. Science 1986, 232:1644-1646.

3. Ross JS, Fletcher JA: HER-2/neu (C-erb-B2) gene and protein in breast cancer. Am J Clin Pathol 1999, 112:53-67.

4. Slamon DJ, Clark GM, Wong SG, Levin WJ, Ullrich A, McGuire WL: Human breast cancer: correlation of relapse and survival with amplification of the Her-2/neu oncogene. Science 1987, 235:177-182.

5. Sjogren S, Inganas M, Lingren A, Holmberg L, Bergh J: Prognostic and predictive value of c-erbB-2 overexpression in primary breast cancer, alone and in combination with other prognostic markers. J Clin Oncol 1998, 16:462-469.

6. Borg A, Baldetorp B, Ferno M, Kilander D, Olsson H, Ryden S, Sigurdsson H: ERBB2 amplification is associated with tamoxifen resistance in steroid-receptor positive breast cancer. Cancer Lett 1994, 81:137-144.

7. Carlomagno C, Perrone $F$, Gallo $C$, De Laurentiis M, Lauria R, Morabito A, Pettinato G, Panico L, D'Antonio A, Bianco AR, DePlacido S: c-erbB-2 overexpression decreases the benefit of adjuvant tamoxifen in early stage breast cancer without axillary lymph node metastases. J Clin Oncol 1996, 14:2702-2708.

8. Tetu B, Brisson J, Plante V, Bernard P: p53 and c-erbB-2 as markers of resistance to adjuvant chemotherapy in breast cancer. Mod Pathol 1998, 11:823-830.

9. Cobleigh MA, Vogel CL, Tripathy D, Robert NJ, Scholl S, Fehrenbacher L, Wolter JM, Paton V, Shak S, Lieberman G, Slamon DJ: Multinational study of the efficacy and safety of humanized anti-HER2-overexpressing metastatic breast cancer that has progressed after chemotherapy for metastatic disease. $J$ Clin Oncol 1999, 17:2639-2348.

10. Jacobs TW, Gown AM, Yaziji H, Barnes MJ, Schnitt SJ: Specificity of HercepTest in determining Her-2/neu status of breast cancers using the United States Food and Drug Administrationapproved scoring system. J Clin Oncol 1999, 17:1983-1987.

11. Tubbs RR, Pettay JD, Roche PC, Stoler MH, Jenkins RB, Grogan TM: Discrepancies in clinical laboratory testing of eligibility for trastuzumab therapy; apparent immunohistochemical falsepositive do not get the message. J Clin Oncol 2001, 19:2714-2721.

12. Park K, Kim J, Lim S, Han S, Lee JY: Comparing fluorescence in situ hybridization and chromogenic in situ hybridization methods to determine the Her2/neu status in primary breast carcinoma using tissue microarray. Mod Pathol 2003, 26:937-943.

13. Elston CW, Ellis IO: Pathological prognostic factors in breast cancer: I. The value of histologic grade in breast cancer experience from a large study with long-term follow-up. Histopathology 1991, 19:403-310.

14. Corbett IP, Henry JA, Angus B, Watchorn CJ, Wilkinson L, Hennessy C, Gullick WJ, Tuzi NL, May FE, Westley BR et al.: NCLCB11, a new monoclonal antibody recognizing the internal domain of the c-erbB-2 oncogene protein effective for use on 
formalin-fixed, paraffin-embedded tissue. J Pathol 1990, 161:15-25.

15. Press MF, Hung G, Godolphin G, Slamon DJ: Sensitivity of Her$2 / n e u$ antibodies in archival tissue samples: potential source of error in immunohistochemical studies of oncogene expression. Cancer Res 1994, 54:2771-2777.

16. Thomson TA, Hayes MM, Spinelli JJ, Hilland E, Sawrenko C, Phillips D, Dupuis B, Parker RL: Her-2/neu in breast cancer: interobserver variability and performance of immunohistochemistry with 4 antibodies compared with fluorescent in situ hybridization. Mod Pathol 2001, 14:1079-1086.

17. Couturier J, Vincent-Salomon A, Nicolas A, Beuzeboc P, Mouret E, Zafrani B, Sastre-Garau X: Strong correlation between results of fluorescent in situ hybridization and immunohistochemistry for the assessment of the ERBB2 (Her-2/neu) gene status in breast carcinoma. Mod Pathol 2000, 13:1238-1243.

18. Jimenez RE, Wallis T, Tabasczka $P$, Visscher DW: Determination of Her-2/neu status in breast carcinoma: comparative analysis of immunohistochemistry and fluorescent in situ hybridization. Mod Pathol 2000, 13:37-45.

19. Pauletti G, Godolphin W Press MF: Detection and quantification of Her2/neu gene amplification in human breast cancer archival material using fluorescence in situ hybridization. Oncogene 1996, 13:63-72.

20. Kakar S, Puangsuvan N, Stevens JM, Serenas R, Mangan G, Sahai $S$, Mihalov ML: Her-2/neu assessment in breast cancer by immunohistochemistry and fluorescence in situ hybridization: comparison of results and correlation with survival. Mol Diagn 2000, 5:199-207.

21. Tanner M, Gancberg D, Di Leo A, Larsimont D, Rouas G, Piccart $\mathrm{MJ}$, Isola J: Chromogenic in situ hybridization: a practical alternative for fluorescence in situ hybridization to detect HER-2/ neu oncogene amplification in archival breast cancer samples. Am J Pathol 2000, 157:1467-1472.

22. Kumamoto $H$, Sasano $H$, Taniguchi $T$, Suzuki $T$, Moriya $T$, Ichinohasama R: Chromogenic in situ hybridization analysis of HER2/neu status in breast carcinoma: application in screening of patients for trastuzumab (Herceptin) therapy. Pathol Int 2001, 51:579-584.

23. Dandachi N, Dietze O, Hauser-Kronberger C: Chromogenic in situ hybridization: a novel approach to a practical and sensitive method for the detection of HER2 oncogene in archival human breast carcinoma. Lab Invest 2002, 82:1007-1014.

24. Zhao J, Wu R, Au A, Marquez A, Yu Y, Shi Z: Determination of Her2 gene amplification by chromogenic in situ hybridization (CISH) in archival breast carcinoma. Mod Pathol 2002, 15:657-665.

25. Gupta D, Middleton LP, Whitaker MJ, Abrams J: Comparison of fluorescence and chromogenic in situ hybridization for detection of Her-2/neu oncogene in breast cancer. Am J Clin Pathol 2003, 119:381-387.

26. Arnould L, Denoux Y, MacGrogan G, Penault-Llorca F, Fiche M, Treilleux I, Mathieu MC, Vincent-Salomon A, Vilain MO, Couturier $\mathrm{J}$ : Agreement between chromogenic in situ hybridization (CISH) and FISH in the determination of Her2 status in breast cancer. Br J Cancer 2003, 88:1587-1591.

27. Park K, Kim J, Lim S, Han S, Lee JY: Comparing fluorescence in situ hybridization and chromogenic in situ hybridization methods to determine the Her2/neu status in primary breast carcinoma using tissue microarray. Mod Pathol 2003, 26:937-943.

28. Vera-Roman JM, Rubio-Martinez LA: Comparative assays for the HER-2/neu oncogene status in breast cancer. Arch Pathol Lab Med 2004, 128:627-633.

29. Ross JS, Fletcher JA, Bloom KJ, Linette GP, Stec J, Clark E, Ayers $M$, Symmans WF, Pusztai L, Hortobagyi GN: Her-2/neu testing in breast cancer. Pathol Patterns Rev 2003, 120:53-71.

30. Sapino A, Coccorullo Z, Cassoni P, Ghisolfi G, Gugliotta P, Bongiovanni M, Arisio R, Crafa P, Bussolati G: Which breast carcinomas need Her2/neu gene study after immunohistochemical analysis? Results of combined use of antibodies against different c-erbB2 protein domains. Histopathology 2003, 43:354-362.

31. Cowell JK: Double minutes and homogeneously staining regions: gene amplification in mammalian cells. Annu Rev Genet 1982, 16:21-59.

32. Sauer T, Wiedswang G, Boudjema G, Chirstensen H, Karesen R: Assessment of HER-2/neu overexpression and/or gene amplification in breast carcinomas: should in situ hybridization be the method of choice? APMIS 2003, 111:444-450.

33. Sidoni A, Cavaliere A, Belleza G, Scheibel M, Bucciarelli E: Breast cancer in young women: clinicopathologial features and biological specificity. Breast 2003, 12:247-250.

34. Albain KS, Allred DC, Clark GM: Breast cancer outcome and predictors of outcome: are there age differentials? J Natl Cancer Inst Monogr 1994, 16:35-42.

35. Hoff ER, Tubbs RR, Myles JL, Procop GW: Her2/neu amplification in breast cancer: stratification of tumor type and grade. Am J Clin Pathol 2002, 117:916-921. 